\title{
A Study on Colleges and Universities Serving Local Economy from the Perspective of Industry-university-research Integration
}

\author{
Huang Mingyue $^{1} \quad$ Yang Guangmin $^{2 *}$ \\ ${ }^{1}$ Pysical Education College of Dalian University, Dalian, Liaoning, 116622; \\ ${ }^{2}$ Foreign Affairs Office, Dalian, Liaoning, 116622
}

\begin{abstract}
:
Industry-university-research integration is a unity which establishes the university-centered integration of education, scientific research and production. This unity is of very practical guiding importance to boost local economy, enhance regional economic vitality, and ensure school running characteristics and education quality of universities. That enterprises collaborate with universities to repay society is an expansion of universities serving society function and a significant program for public good. Meanwhile, this collaboration is a useful practice to implement the strategies of developing the country through science and education and strengthening the country through talents, and is an important measure to promote the construction of a harmonious society.
\end{abstract}

Keywords: Industryuniversityresearch Integration; Serving the Local; Economic Development

Industry-university-research integration is a unity which establishes the university-centered integration of education, scientific research and production. This integration is also a cooperative association constituted by enterprises, universities and scientific research institutions on the basis of resource sharing, complementary advantages, business connection and interests sharing. The cooperative association devotes itself to the close integration of fundamental research, development research and applied research. It has an important practical guiding significance to promote regional economic development, improve the regional economic vitality, guarantee and improve the education quality and school-running characteristics. "Exploring the mode of university-industry-enterprise joint close collaboration and joint development, promoting university-scientific research institution-social organization resource sharing, developing effective mechanisms for coordination and cooperation, and improving the ability of serving the economic construction and social development" [1]

Fund Program: The Research Result of Liaoning College Students' Innovation and Entrepreneurship Training Program (No.: 201211258008); The Result of 2012 Liaoning Regular Higher Education Undergraduate Teaching Reform Research Program: "A Study on Colleges and Universities Serving Local Economy from the Perspective of Industry-university-research Integration";

About the Author: Huang Mingyue (1990--), female, Yichun, Hei Longjiang, undergraduate.

Corresponding Author: Yang Guangmin (1971-), Male, Dalian Liaoning, instructor, master, major in higher education research. E-mail:yangguangmin@dlu.edu.cn 
has been clearly proposed in National Education Reform and Development of Long-term Planning Programs (2010-2012). In this background, people pay more and more attention to the improvement of the ability of colleges and universities to serve the economic construction and social development. The effects of cooperation between university and enterprise on

At present, the promotion of industry-university-research integration has become not only the inevitable choice of China's practice of sustainable development strategy and the strategy of rejuvenating the country through science and education, but the urgent and internal requirement for enterprises and universities to change the present situation. New requirements for industry-university-research integration have been put forward in National Education Reform and Development of Long-term Planning Programs (2010-2012) and The Ministry of Education "2011 Plan" from the aspects of personnel training, scientific research, social services, etc.. New countermeasures should be proposed in the creation of the mechanism of talents jointly cultivated by universities, research institutes, industry and enterprises; the innovation forces at home and abroad should be actively united to assemble innovation elements and resources effectively, build a new model of collaborative innovation. In this way, the unique role of higher education as an important joint point of science and technology as the primary productive force and talents as the primary resource can be brought into full play, which makes greater contribution to the development of national innovation. The heavy chemical industry-oriented industrial structure in Liaoning had been formed after the foundation of New China. The problem of industrial structure in Liaoning province has becoming increasingly obvious with the further development of market economy: a large number of enterprises are short of high-technology the economic construction and social development of Liaoning province have been studied in this paper under the perspective of industry-university-research integration.

\section{The Value Analysis of the Cooperation Between University and Enterprise Serving Liaoning Under the Perspective of Industry-university-research Integration}

support and lag in key technology. "Vigorously implementing the strategy of rejuvenating the province through science and education and talents strategy, and comprehensively promoting the strategic adjustment of Liaoning's economic structure and industrial structure" has been taken by Liaoning Provincial Party Committee and the Provincial Government as the major strategy to revitalize Liaoning old industrial bases. Wang Min, secretary of Provincial Party Committee, has emphasized in the report of the Eleventh Liaoning Congress of Party Representatives that "the potentials of the institutions of higher learning and scientific research should be brought into full play to achieve major breakthroughs in a number of core and key technologies, form a group of major strategic products with independent intellectual property rights, and promote the industry transformation and upgrading. The improvement of enterprise innovation ability should be accelerated to make enterprises the subject of technical innovation; the industrial technology innovation strategic alliance should be constructed to improve technology innovation system of industry-university-research integration. The science and technology input should be increased and the entrepreneurial venture investment should be developed to promote the demutualization of the human capital and technology. Meanwhile this will promote the integration of technology, finance, capital, resources and market, accelerating the commercialization of research findings and improving the contribution rate of technological 
innovation." [2] As an effective mode of the innovation system of universities serving the local, industry-university-research integration

2. Survey on the Development Situation of Industry-university-research Integration in the Universities of Liaoning

Liaoning province is a large province of industry, education as well as technology with good conditions for the construction of industry-university-research integration development. Since the first large fair of industry-university-research cooperation project held in Liaoning province in 1992, the annual fair on industry-university-research integration held in Liaoning has been quite influential in China and has attracted a large number of has become the central link to promote the the industrial restructuring, optimization and upgrading of Liaoning old industrial base.

universities and research institutes. Many scientific cooperative projects have been decided in this fair. The appropriation expenditure spent by scientific research institutions, large and medium-sized enterprises from 2005 to 2011 on research and development (see the figure below) was listed by Liaoning Provincial Bureau of statistics in the "2012 Liaoning Statistical Yearbook" $^{[3]}$, from which we can see be it scientific research institutions or medium-sized enterprises, their appropriation expenditure is constantly increasing.

The Basic Information of Scientific Research and Development Institutions

\begin{tabular}{l|l|l|l|l|l|l|l}
\hline Indicators & \multicolumn{1}{|c|}{ Unit } & 2005 & 2006 & 2008 & 2009 & 2010 & 2011 \\
\hline Expenditure of R\& D & Hundred Million Yuan & 11.20 & 12.00 & 16.90 & 31.10 & 44.15 & 45.74 \\
\#Fundamental Research & Hundred Million Yuan & $\mathbf{1 . 0 0}$ & $\mathbf{1 . 3 0}$ & $\mathbf{1 . 8 0}$ & $\mathbf{2 . 6 0}$ & $\mathbf{3 . 2 6}$ & $\mathbf{3 . 6 9}$ \\
Applied research & Hundred Million Yuan & 3.20 & 4.00 & 5.90 & 12.30 & 14.66 & 16.05 \\
Experimental & Hundred Million Yuan & 5.00 & 3.00 & 6.10 & 16.20 & 26.22 & 26.01 \\
Development & & & & & & & \\
\hline
\end{tabular}

The Basic Information of the Large and Medium-sized Industrial Enterprises

\begin{tabular}{l|c|c|c|c|c|c|c}
\hline Indicators & Unit & 2005 & 2006 & 2008 & 2009 & 2010 & 2011 \\
\hline $\begin{array}{l}\text { Expenditure of R\&D } \\
\text { Appropriation }\end{array}$ & Hundred Million Yuan & 84.3 & 85.9 & 129.0 & 166.4 & 191.3 & 238.2 \\
$\begin{array}{l}\text { Expenditure of } \\
\text { Technology Import }\end{array}$ & Hundred Million Yuan & 9.3 & 19.4 & 22.7 & 27.4 & 6.4 & 3.5 \\
$\begin{array}{l}\text { Expenditure for } \\
\text { Assimilation of }\end{array}$ & Hundred Million Yuan & 0.8 & 2.1 & 3.2 & 4.7 & 4.6 & 3.0 \\
$\begin{array}{l}\text { Technology } \\
\text { Expenditure of }\end{array}$ & & & & & & & \\
$\begin{array}{l}\text { Purchasing Domestic } \\
\text { Technology }\end{array}$ & Hundred Million Yuan & 1.2 & 2.8 & 20.3 & 18.9 & 15.8 & 17.4 \\
\hline
\end{tabular}

(Data Source: 2012 Liaoning Statistical Yearbook)

In 2006, an expenditure of 20,000,000 Yuan was arranged in Liaoning province to support enterprises to establish technical alliances with scientific research institutions and universities. The support was focused on 24 enterprises such as Shenyang Blower Group, Liaohe Oilfield, 
Fushun Excavator Manufacturing Company, Dalian Machine Tool Group, etc.. These enterprises established technical alliances with 17 universities like Dalian University of Technology, Northeastern University, Chinese Academy of Sciences Shenyang Institute of Automation, etc. and 4 research and development institutions with a support from hundreds of thousands of Yuan to several hundred million Yuan. Only Shenyang Blower Group got a 3,000,000 Yuan support, taking the first place among all alliances. Since 2007, Liaoning province had spared no effort to promote the construction of enterprise technical alliance and had proposed that until 2010 the research direction and focus of universities and scientific research units should meet the need of economic development and enterprise competitions; the modes and methods of enterprise, university and research cooperation should be continuously innovated with more flexible cooperative mechanism to form a number of technical alliance based on the close cooperation of industry, university and research. In the March of 2012 the Ministry of Education and the Ministry of Finance launched a comprehensive implementation of "Innovation Ability Enhancement in Institutions of Higher Learning Plan". On November 9, 2012, led by Dalian University of Technology, Shenyang University of Technology, a group of units, such as Shenyang University of Technology, Dalian Jiaotong University, CAS Shenyang Institute of Automation, Shenyang Blower Group Co. Ltd., Northern Heavy Industries Group Co., Ltd., Dalian shipbuilding Industry Group Co., Ltd. and so on, launched the Collaborative Innovation Center for High-end Equipment. This center, set up in Dalian University of Technology, is the collaborative innovation result of universities, scientific research institutions and enterprises. It can promote the organic combination of higher education with technology, economy and culture, and can vigorously promote the innovation ability of colleges and universities. In recent years, the development of industry-university-research alliance in Liaoning, from the proposal of the technical alliance slogan to the formation of the technical alliance project, from 24 technology alliances to 247 technology alliances and from the task deployment to the policy guarantee, has shown the determination of Liaoning province to promote the industry-university-research cooperation to a higher level determination. ${ }^{[4]}$

\section{The Thoughts and Countermeasures on the Development of}

\section{Industry-university-research Integration in the Universities of Liaoning}

\subsection{The Thoughts and Countermeasures on the Development of \\ Industry-university-research Integration in the Universities of Liaoning}

Extensive research should be carried out and the experience and relevant policies of industry-university-research integration in universities should be understood; the purpose is to help promote substantive cooperation, mobilize the enthusiasm of all parties, and follow the principle of combining macro management with micro adjustment. The school's relevant policies about industry-university-research integration shall be studied, formulated and demonstrated, including ways of cooperation, management methods, incentive measures, etc.. In the industry-university-research integration process, key technologies and fields as well as colleges and enterprises with corresponding advantages should be selected based on the significant demands of the industry's self-development to build the distinctive cooperation mode of industry-university-research integration. 
3.2 Co-construction of the Enterprise Demands-oriented Platform for the Cultivation of Application-oriented Innovative Talents

The university talent training platform should be jointly built through the active engagement of all parties in industry-university-research cooperation. "Application" is the crux and the ultimate goal of the cultivation of application-oriented innovative talents, transforming knowledge into practical ability and into real productivity and creativity. Emphasis should be placed on the communication and cooperation between enterprises and public institutions in the university-oriented education in order to cultivate application-oriented innovative talents with a strategic insight. Furthermore, the diversity and stability of the talent training platform should be realized through the institutional improvement such as "bringing in and going out" strategy, the formulation of training plan, curriculum adjustment, the increase of internship and practical training and so on.

\subsection{Vigorous Development of}

University-oriented

\section{Industry-university-research Cooperation}

\section{Education}

Industry-university-research cooperation education in university is an education mode by which enterprises' educational resources and educational environment are utilized by universities to cultivate innovative talents in cooperation with enterprises. The empirical research on the industry-university-research integration development in Liaoning should be carried out to study how to forge distinctive and multiform school-enterprise cooperation modes oriented by universities and supplemented by enterprises. In addition, the ways of universities to take advantages of their teachers, discipline construction, teaching and research should be studied; finally the ways of enterprises' involvement should be studied to give an timely introduction and guidance on the basic situation of economic society, the primary demand of market and enterprise, and the basic building block and criterion of talent structure and level to education subject and object

3.4 The Development of the Advantages of Multi-disciplinarity and Multi-functions of Universities to Build the "2011 Collaborative Innovation Center" Geared to the Needs of

\section{Liaoning}

Led by The local government, the center should focus on practically serving the regional economy and social development. The advantages of multi-disciplinarity and multi-functions of universities should be brought in to play to absorb the participation of scientific research institutions, industries, enterprises, the local government and international innovative forces with colleges and universities as the subject of implementation. The center can become the leading position for regional innovation and development through motivating the deep integration of the colleges and universities inside and outside the province with key enterprises or industrialization bases in the pillar industry of Liaoning.

\section{References}

[1] National Education Reform and Development of Long-term Planning Programs (2010-2012).

[2] http://www.360doc.com/content/11/1104/13/ 2657285_161614663.shtml.

[3] http://bbs.jjxj.org/thread-1170161-1-1.html

[4] Feng Xuefei and Dai Lixin. "A Study on Innovation and Development of the Industry-university-research Institute Alliance: Under the Perspective of Industry Cluster Theory". Scientific and Technological Progress and Countermeasures, 2011, （10）: 39. 